\title{
NANOMATERIALS - A NEW AND FORMER PUBLIC HEALTH ISSUE. THE CASE OF SLOVAKIA
}

\author{
Stanislav Kuka', Marta Hurbánková2, Martina Drličkováa ${ }^{2,3}$, Tibor Baška ${ }^{1}$, Henrieta Hudečková1, Zuzana Tatarková1 \\ ${ }^{1}$ Jessenius Faculty of Medicine in Martin, Comenius University in Bratislava, Martin, Slovak Republic \\ ${ }^{2}$ Faculty of Public Health Studies, Slovak Medical University, Bratislava, Slovak Republic \\ ${ }^{3}$ Centre for Chemical Substances and Preparations, Ministry of Economy of the Slovak Republic, Bratislava, Slovak Republic
}

\section{SUMMARY}

Nanoparticles exist for a long time as both inorganic and organic parts of nature. Recently, massive expansion of nanotechnologies is evidenced, together with intentional production of new nanoparticles which have not been in contact with living organisms until now. Besides obvious positive aspects, potential threats related to their exposure should be taken into consideration. Unique physical-chemical properties of nanoparticles cause a high bioactivity following their intake (through air, ingestion and skin) and unrestricted spread in exposed organs. Primary effects of nanoparticles on cellular level represent oxidative stress and reactions leading to apoptosis, autophagocytosis and necrosis. Number of studies indicating contribution of nanoparticles to numerous disorders has been recently increasing. However, detailed mechanisms of health effects are not well known. Similarly, there is insufficient information on life cycle of nanoparticles in the environment. Research in this field as well as legislation is behind rapid development and use of nanotechnologies. Considering absence of mandatory exposure limits and other protective measures, nanomaterials represent a potential threat for population health. Recommendations and guidelines of international institutions can contribute to deal with situation, however, passing of effective legislation both on national and European level is urgently needed.

Key words: nanomaterials, nanoparticles, environmental hazard, population health, exposure limits

Address for correspondence: S. Kuka, Department of Public Health, Jessenius Faculty of Medicine in Martin, Malá Hora 4B, 03601 Martin, Slovak Republic. E-mail: kuka@jfmed.uniba.sk

http://dx.doi.org/10.21101/cejph.a4872

\section{INTRODUCTION}

Nanoparticles, nanomaterials and nanotechnology represent concepts that are increasingly used by professionals and lay people. This stems from the massive expansion of their development and use in recent years, which opens new opportunities in many fields of human activities.

The European Commission defines nanomaterial as a natural, incidental or manufactured material containing particles, in an unbound state or as an aggregate or agglomerate and where, generally for $50 \%$ or more of the particles in the number size distribution, one or more external dimensions is in the size ranging from $1-100 \mathrm{~nm}$. Fullerenes, graphene flakes and single wall carbon nanotubes with one or more external dimensions below $1 \mathrm{~nm}$ should be considered as nanomaterials (1).

Why is this both new and former issue? Nanoparticles (NP) are present in the environment much longer than the last few decades - for example, as part of smoke accompanying volcanic activity or combustion of various materials. The NP concept includes also subcellular structures (nucleus of the cell, mitochondria, cell membranes), DNA macromolecules, viruses, etc. However, new profits but also risks are brought about by the targeted production of new NP that have not been met by living organisms. It may therefore happen that human defence mechanisms fail and would not be able to react appropriately to newly created particles and know how to prevent their potential negative effects. Each un- known and, in terms of biological effects, unexplored substance - as the toxicity of most engineered NP is unknown - may have a potentially harmful impact on individuals and population health. Despite the unquestionable positives, it is necessary to take into consideration the potential risks resulting from their long-term deleterious exposure.

\section{CURRENT KNOWLEDGE}

\section{Characteristics of Nanoparticles}

A comparison between the size of NP and other known objects is shown in Figure 1 (2). As the dimensions of NP are close to the dimensions of basic material particles (atoms, molecules), quantum phenomena start to apply and NP acquire unique physical and chemical characteristics, which are not shown in the substance in the form of larger particles (3). In particular, quantum restriction on the movement of electrons in nanoparticles and a relatively large surface of the nanoparticles as a place of interaction of nanoparticles with the environment are considered to be the direct causes of changes in the properties (4). For instance, one microparticle having a diameter of $60 \mu \mathrm{m}$ (human hair) corresponds to the weight of 1 billion nanoparticles of $60 \mathrm{~nm}$ in diameter, the surface of which is a thousand times greater than the considered nanoparticle. Changes in the physicochemical 


\begin{tabular}{|c|c|c|c|}
\hline \multicolumn{2}{|r|}{ SIZE } & \multicolumn{2}{|r|}{ EXAMPLES } \\
\hline \multirow{4}{*}{ 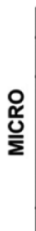 } & $1 \mathrm{~mm}$ & 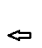 & lung alveoli $(400 \mu \mathrm{m})$ \\
\hline & $100 \mu \mathrm{m}$ & 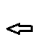 & hair (diameter $60 \mu \mathrm{m}$ ) \\
\hline & $10 \mu \mathrm{m}$ & ๘ه & red blood cell $(7 \mu \mathrm{m})$ \\
\hline & $1 \mu \mathrm{m}$ & 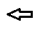 & bacteria $(0,3-2 \mu \mathrm{m})$ \\
\hline \multirow{4}{*}{$\begin{array}{l}\frac{0}{2} \\
\frac{\mathbf{s}}{z}\end{array}$} & $100 \mathrm{~nm}$ & ڤه & virus $(10-150 \mathrm{~nm})$ \\
\hline & $10 \mathrm{~nm}$ & ৫ & combustion exhaust $(20 \mathrm{~nm})$ \\
\hline & $1 \mathrm{~nm}$ & 灾 & $\begin{array}{l}\text { DNA helix (diameter } 2 \mathrm{~nm}) \\
\text { fullerene } C 60(1 \mathrm{~nm})\end{array}$ \\
\hline & $0,1 \mathrm{~nm}$ & ڤ & atom $(0,1 \mathrm{~nm})$ \\
\hline
\end{tabular}

Fig. 1. Comparison of micro-objects with nano-objects. Edited according to Buzea et al. (2).

properties concern in particular the change of solubility in polar and non-polar solvents, changes in electrical potential and electrical conductivity, changes in colour and fluorescence, changes in refractive index and absorption of light. A significant change in chemical reactivity: increased reactivity is associated with an increase in the surface energy of several orders of magnitude while reducing the volume of particles into nanoscale $(4,5)$.

The nanoparticles have spherical, tubular or irregular shape (6). NP properties depend primarily on their size. A substance consisting of NP has different properties than the same substance composed of larger particles, for example microparticles having the size of microns. Particles and nanoparticles of the same substance can have completely different effects on the human body. Also nanoparticles of different sizes may have different effects and different reactivity rate (6). A demonstrative example of that phenomenon is the pyrophoric behaviour of nanoiron that spontaneously ignites in contact with atmospheric oxygen (5).

\section{Use of Nanoparticles}

The production and use of intentionally prepared NP and nanomaterials (NMs) have increased rapidly over the last ten years: the total quantities delivered to the world markets are estimated at millions of tons per year with an annual increase in production of about $50 \%$, which corresponds to about 10 fold increase in six years. The most represented materials in the current production are carbon black (for rubber products) and amorphous silica. The most progressive increases occur in the production of nanocrystalline oxides $\left(\mathrm{SiO}_{2}, \mathrm{TiO}_{2}, \mathrm{ZnO}, \mathrm{FeOx}\right.$, $\mathrm{AlOx}, \mathrm{CeOx}$ - oxides of silicon, titanium, zinc, iron, aluminium, cerium), fullerenes (e.g. C60), carbon nanotubes, nanosilver, nanoiron, and other $(7,8)$.

\section{Nanoparticles in Workplaces}

The application of NMs and nanotechnology is expanding rapidly and currently includes: active fillers in rubber industry, plastic industry and manufacture of paints, additives for concrete, cosmetic products (toothpaste, hair products, sunscreen), drugs, UV-filter of glasses, and top information technology. They are used in textiles, electronics, optics, engineering, automotive, military, aerospace, chemical, consumer goods industry, food, pharmacy, medicine (therapy, diagnostics), and other sectors. Workers are professionally exposed to nanoparticles in the production of NP, in the manufacture of products from NP - especially synthetic, their processing, packaging, cleaning and maintenance. Workers involved in the development, research, production of NP and nanomaterials, and personnel involved in working activities such as cutting, grinding of products made of nanomaterials and in cleaning of manufacturing equipment are more exposed (higher concentration, longer exposure times) than the general population of consumers. Occupationally exposed to nanoparticles are also workers in construction work, decorators and painters, welders, workers in nanotechnology, professional drivers exposed to exhaust gas in maintenance and repair of cars, workers exposed to raw NMs and waste in working process, hairdressers, researchers, healthcare personnel in therapy and diagnostics etc. (3).

\section{Nanoparticles in the Environment}

The development of NMs applications brings the need for careful mapping of the risks associated with their production and the entire life cycle in the environment. NP are present in the atmosphere mainly in the form of condensation particles such as fine crystals of ice, smoke particles caused by fires, particles in explosion or smouldering volcanoes, incineration - especially of fossil fuels (fuel for automobiles, coal) in industrial activities (smog), when smoking (particulate matter from cigarette smoke breathed by smokers and passive smokers), etc.

The existing risks are clearly demonstrated by the environmental contamination by nanoparticles that have been undesirable since their origination - combustion derived nanoparticles (CDNP). Their biggest sources include combustion engines of vehicles. Exhaust gases are currently the largest contribution to urban air pollution by solid aerosols - particulate matter (PM), in which CDNP is the most significant toxic component (9). In the cities - especially in intersections there is a high concentration of NP from diesel engines or cars that have defective or cold catalytic converters. Sometimes a litre of air can contain millions NP.

The production of NP and NMs grows from year to year, which naturally leads to an increase in waste materials that plague the environment. Polluted environment can cause chronic exposures in humans via the food chain. Waste materials can also pollute the air. This situation triggers concerns about the potential risk of NP for ecosystem and consequently the health of exposed people. NP can get into the environment, for example, by destruction at the end of "life" of final products such as bumpers of passenger cars made of polymers with carbon nanotubes reinforcement, etc. (10).

\section{Health Effects of Nanoparticles}

NP adverse effects on human health depend on individual factors such as genetic predisposition, whether a disease is present, length and intensity of exposure. Further, risks depend on the properties of NP, i.e. the size (dimensions), the surface area and reactivity, dosage, chemical composition, shape, solubility, ability to form aggregates or agglomerates, surface finish and their structure (11).

It is obvious from the existing research that exposure limits for NMs will be different from the limits of the substances in the 
form of larger particles and the definition of limits will require more than one variable - concentration of the substance (8).

It follows from the present knowledge of the relationship between NP and the human body $(2,3,5,8,9,12-21)$ that:

- NP can penetrate into the body in several ways: lungs (living and working environment), skin (cosmetics, clothing), and digestive tract (food and medicines) (12). In the body they may penetrate through biological barriers into many organs and tissues, cells and cell structures, and produce undesirable toxic effects $(8,13)$. They most often penetrate into the body through the respiratory tract as an aerosol (5). To a large extent, they settle in alveolar sac where they can leak through alveolar macrophage and interact with lung epithelial cells.

- Nanoparticles can spread in the body via the circulatory system, the lymphatic system and also the nervous system through the olfactory nerves $(2,14)$.

- Because of the large surface and the changed physical-chemical characteristics of the substances in the NP form, their bioactivity in the body is usually significantly increased compared to the substance in the form of larger particles. The primary effect is usually a pro-inflammatory activity as a result of the catalyzed formation of free radicals and other reactive compounds inducing oxidative stress (9). This appears to be a potential marker for determining the toxicity of nanomaterials, or the risk of damaging DNA (15). After NP enter the cellular structures (nucleus, phagosomes, lysosomes, mitochondria), reactions may be activated, e.g. DNA fragmentation, leading gradually to apoptosis, autophagocytosis or necrosis (16).

- The consequences of the action of NP are inflammation, destruction of lung tissue, asthma, bronchitis, emphysema, lung cancer or industrial lung diseases - silicosis, asbestosis (3). Also participation of NP in the pathogenesis of atherosclerosis, thrombus, arrhythmia (cardiovascular system), Parkinson and Alzheimer's disease (brain), Kaposi's sarcoma (lymphatic system) $(3,17)$. Other organs affected may be the liver, spleen and kidneys (14). NP received through the digestive system may interact in the pathogenesis of cancer of the colon and Crohn's disease $(2,18)$. NP in contact with the skin can be received by the cells using the epidermal keratinocytes, which explains dermatological reactions in workers exposed to nanoparticles of beryllium and other substances $(2,14,19)$.

Recent epidemiological studies have shown a strong correlation between the level of air pollution by particles and respiratory diseases, cardiovascular diseases, various cancers and mortality (2). The professional drivers have an increased incidence of myocardial infarction, which may be partly caused by the exposure to nanoparticles (6).

\section{CURRENT RESEARCH}

Despite these facts on the effects of NP it can be concluded that detailed mechanisms of the action of NP on living organisms have not yet been well known, which is true also for the following data:

- properties of NP in general, as well as properties of NP in the food and biological matrix;

- analytical methods for NP in general, as well as for NP in the food and biological matrix;

- the routes of exposure to nanoparticles;
- toxicokinetics of nanoparticles;

- potential toxicity of NP and NMs, i.e. the data essential for estimating the risks of the use of NMs (20).

The research should focus on addressing issues such as the mechanism of penetration of NP into the cell, transport of NP to other tissues and organs, persistence of NP in tissues and organs, target molecules with which NP interact in the cell, kinetics and elimination of NP from the target tissue, defence response of the body to the NP exposure, the interaction of NP with different physical factors and chemicals in the environment and working environment etc. (21). Furthermore, it should focus on defining the parameters for quantifying exposure to nanoparticles, methodologies for measuring the exposure and determination of exposure limits, and also on the development of effective methods to decrease exposure to NPs. Moreover, the research studying this issue from the perspective of population should be extended to estimation of population attributable risk and subsequent estimation of the impacts on different target populations, as well as the potential population benefit of preventive interventions.

\section{RESEARCH IN SLOVAKIA}

In Slovakia, the research focuses in particular on the issue of health hazards associated with nanoparticles and several institutions are involved in major international projects in this area. The Faculty of Public Health Studies of the Slovak Medical University in Bratislava is dedicated to the health and environmental impact of nanomaterials, and also to the development of methodology for alternative testing strategies for the assessment of the toxicological profile of nanoparticles used in medical diagnostics $(3,12,13)$. The Faculty of Chemical and Food Technology STU Bratislava - Department of Physical Chemistry and Chemical Physics (20) participates in the working group of the European Food Safety Authority (EFSA) for nanotechnologies focused on the risk assessment of the application of nanotechnologies in the food and feed chain. Furthermore, the Cancer Research Institute of the Slovak Academy of Sciences Bratislava (EU FP7 project "The risk assessment of engineered nanoparticles on human and ecosystem health: Understanding the problem") and the Chemical and Pharmaceutical Industry Association (CPIA SR), which is involved in the international project NANOFORCE aimed to link scientific advances in NMs with business in Central Europe. An important part of the project consists of nanosafety and activities in the relevant EU legislation $(22,23)$. Within the project, CPIA periodically organizes conferences and other specialized actions aimed at responsible use of nanomaterials $(24,25)$. One member of staff from the Centre for Chemical Substances and Preparations of the Ministry of Economy has participated in the creation of EU legislation in the field of chemicals including nanomaterials (26), as a member of the Nanomaterial Working Group of European Chemical Agency (ECHA-NMWG) and Competent Authorities Sub-Group on Nanomaterials (CASG Nano-REACH). One employee of the Ministry of the Environment is dedicated to nanosafety as a member of the Working Party on Manufactured Nanomaterials of the Organisation for Economic Cooperation and Development (OECD).

In contrast to the neighbouring EU countries, e.g. the Czech Republic, where NP monitoring in the living and working envi- 
ronment has been carried out $(27,28)$, analogous measurements are just being prepared in Slovakia: monitoring of NP in the environment prepared by the Slovak Hydrometeorology Institute (SHMI) Bratislava with the implementation expected during the second half of 2016 (according to unofficial information from SHMI, Monitoring of Emissions and Air Quality section). The Faculty of Public Health Studies of the Slovak Medical University in Bratislava has intended the monitoring and research of NP in the workplace: "Occupational exposure to nanoparticles from welding - welding fumes impact on the health of welders". The issues of NP in the living and working environment starts to be addressed also by the Department of Public Health of the Jessenius Faculty of Medicine in Martin and participation of other departments, which have not been specified yet, is anticipated.

In the Czech Republic, several departments in the European Technology Platform and others deal with the issue of nanotoxicity and nanosafety, for example the Occupational Safety Research Institute in Prague which published Nanosafety (14), also the Faculty of Safety Engineering of the Technical University of Ostrava (8) disposing of a device for NP monitoring.

\section{LEGISLATION AND PREVENTIVE MEASURES}

The legislation related to NMs is expected to ensure the protection of individual health, public health and the environment from potential adverse effects of NP and NMs. It should therefore codify an appropriate framework for the individual nanosafety areas: monitoring, exposure control, exposure limits, protection measures etc. The current state of Slovakia and outside Slovakia is different. The research into the health effects of NP is lagging behind the rapid pace of development of nanotechnologies and the so far unregulated production and introduction of nanomaterials into practice within the EU. Even more lagging is the implementation of research results into relevant legislation. It is clearly presented in Figure 2 edited according to Savolainen et al. (29). Due to low financial resources for research into the nanosafety and other possible causes the delay is gradually increasing.

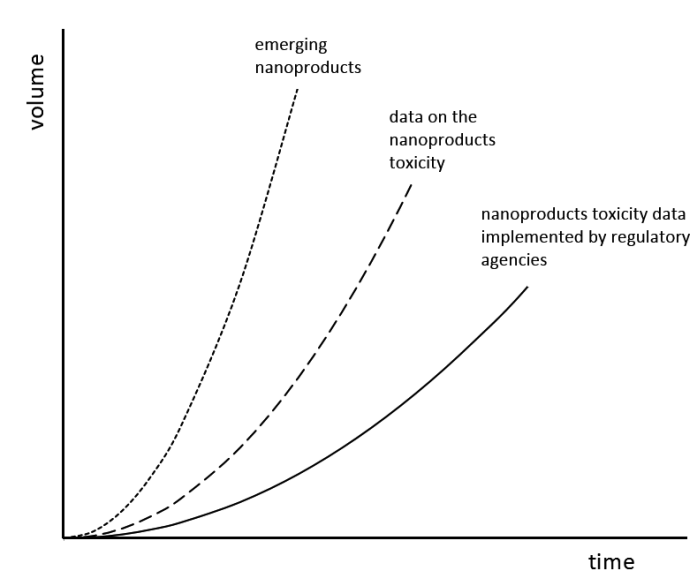

Fig. 2. Delay of regulatory legislation measures compared to nanosafety research and available technological knowledge on manufactured nanomaterials. Edited according to Savolainen et al. (29).
The individual countries have various approaches to assessing the safety of nanotechnology. As regards the US legislation, the US government in Washington have not yet definitively commented on the issue "nanotechnology and human health", but announced plans to deal with this issue more deeply. The National Institute for Occupational Safety and Health (NIOSH), which is an organizational unit of the Centers for Disease Control and Prevention, has been intensively devoted to the nanosafety for more than a decade, as evidenced by the abundant publications (30).

In the European Union, the discussion about regulation of NMs has started several years ago. In the last years, specific provisions for NMs were integrated in some sector specific regulations, e.g. food additives (31), biocidal products (32), cosmetics (33), and plastic materials and articles intended to come into contact with food (34). However, the main chemical regulation No. 1907/2006 concerning the Registration, Evaluation, Authorisation and Restriction of Chemicals (REACH) has remained unchanged so far. The major aim of REACH is to ensure a high level of protection of human health and the environment from the risks that arise from chemicals. REACH applies to all types of substances, regardless to their size, shape or properties. Even though NMs are not explicitly mentioned in $\mathrm{REACH}$, its provisions in principle apply (35). In the Second Regulatory Review on NMs the European Commission (EC) concluded, that REACH sets the best possible framework for the risk management of NMs, but more specific requirements for them are necessary. Furthermore, the risk assessment should be performed on a case-by-case basis, using adequate information. EC stated that shortcomings found in the implementation can be addressed via Annexes modification (36). However, several member states and stakeholders are of the view that revision of the Annexes will not be sufficient to address NMs adequately by REACH $(37,38)$. Whereas EC identified the process of Annexes adaptation as faster and lighter, this approach was finally supported by the majority of member states at least as the first step (38). The entire process of modification of REACH Annexes, which includes an Impact Assessment of REACH Annexes for NMs, is much longer than originally anticipated. EC justifies delay by long and demanding internal discussion. The Commission estimates that draft legal proposal will be ready for adoption in the REACH Committee late 2016. After adoption, it will be subject to the three month examination by the Parliament and Council.

Several European countries are not satisfied with the state of EU legislation on NMs. Some have introduced or are preparing a national register of nanomaterials (e.g. France, Belgium, Denmark, Italy, Sweeden) or national legislation. In Slovakia, such measures are not likely to be under preparation, as Slovakia supports the efforts of the European Commission to implement nanomaterials in the European chemical legislation (according to unofficial information obtained from the Ministry of Economy and the Ministry of Health - the Office of Public Health of the Slovak Republic). However, this process is very lengthy and does not contribute to the preventive nature of REACH.

\section{CONCLUSIONS AND RECOMMENDATIONS}

In Slovakia, the issue of nanomaterials remains far from receiving all the attention it has received in several European countries. 
Although Slovak experts are represented in expert groups at the European (EFSA, ECHA-NMWG, CASG Nano) as well as global level (OECD), there is a lack of mutual communication between them. It would be beneficial to improve intersectoral cooperation between the academic institutions and governmental authorities, notably in the support of research and the subsequent implementation of scientific evidence in the upcoming legislation.

Until effective EU legislation on acceptable risk, exposure limits and other regulatory measures will come into force, nanoparticles pose a potential threat to public health.

\section{Implications for Practice}

The implementation of international experience in Slovakia, i.e. knowledge of organizations and other structures that have been long working in the area of nanosafety, e.g. NIOSH (30), the European Agency for Safety and Health at Work (EU-OSHA) (39), or the Finnish Institute of Occupational Health (40), apply the precautionary principle. Hence the importance of creating basic recommendations for employers and employees.

Applied research should be focused on the current issues of qualitative and quantitative assessment of the exposure to nanoparticles in the workplace, therefore risks can be estimated.

Based on the current findings, to modify the existing and create new measures to reduce risks, which includes an effective reduction of leakage of nanoparticles into the environment, the use of personal protective equipment, shortening exposure times if necessary, and appropriate education of employees should be provided. Employees should regularly undertake preventive medical examinations. Just as safe production and use of nanoparticles is necessary, also safe disposal of the products made of NMs is important (14).

Information exchange among all relevant stakeholders to promote development of effective evidence-based legislative norms both on European and national level to protect occupational and environmental health is necessary.

\section{Conflict of Interests}

None declared

\section{REFERENCES}

1. European Union (EU). Commision recommendation on the nanomaterials definition. Official Journal of the European Union. Legislation [Internet]. Oct 2011 [cited 2016 Feb 19];54(L 257):38-40. Available from: http:// eur-lex.europa.eu/LexUriServ/LexUriServ.do?uri=OJ:L:2011:275:0038 :0040:EN:PDF.

2. Buzea C, Pacheco II, Robbie K. Nanomaterials and nanoparticles: sources and toxicity. Biointerphases. 2007;2(4):MR17-71

3. Hurbánková M, Hrašková D, Moricová Š. Occupational exposure to nanoparticles. Prac Lék. 2014;66(2-3):78-84. (In Slovak.)

4. Fojtík A, Kálal M, Prnka T, Šperlink K, Mašláň M, Zbořil R, et al. NANO - fascinating phenomenon today. Praha: COMTES FTH; 2014. (In Czech.)

5. Nohavica D. Risks of nanomaterials and nanotechnology to human health and environment. Českoslov Čas Fyz. 2011;61(3-4):220-7. (In Czech.)

6. Allhoff F, Lin P, Moore D. What is nanotechnology and what does it matter?: from science to ethics. Chichester: Wiley-Blackwell; 2010.

7. Piccino F, Gottschalk F, Seeger S, Nowack B. Industrial production quantities and uses of ten engineered nanomaterials in Europe and the world. J Nanopart Res. 2012;14:1109. doi: 10.1007/s11051-012-1109-9.
8. Vít M, Danihelka P. Health risks of nanomaterials and the protection of the workplace [Internet]. Prague: NIPH; 2013 [cited 2016 Feb 15]. Available from: http://www.szu.cz/uploads/documents/chzp/prednasky/ milovy/2013/12_vit_nanomaterialy.pdf. (In Czech.)

9. Duffin R, Mills NL, Donaldson K. Nanoparticles - a thoracic toxicology prospective. Yonsey Medical J. 2007;48(4):561-72.

10. Kittelson DB, Johnson JP, Watts WF, Heinzen A. Effects of the U.S. EPA ultra low sulfur diesel fuel standard on heavy-duty fleet average nanoparticle emissions in Minessota: 12th ETH-Conference on Combustion Generated Nanoparticles; June 23rd - 25th 2008; Zurich, Switzerland [Internet]. Zurich: 2008 [cited 2016 Feb 15]. Available from: http://www. nanoparticles.ch/archive/2008_Kittelson_PR.pdf.

11. Warheit DB, Webb TR, Reed KL , Frerichs S, Sayes CM. Pulmonary toxicity study in rats with three forms of ultrafine - TiO2 particles: differential responses related to surface properties. Toxicology. 2007;230(1):90-104.

12. Hurbánková M, Hrašková D, Marcišiaková J, Kysucká K, Moricová Š. Nanoparticles orginating from welding and their impact on health. Prac Lék. 2015;67(1):12-7. (In Slovak.)

13. Hurbánková $M$, Černá $S$, Kováčiková Z, Wimmerová S, Hrašková D, Marcišiaková J, et al. Effect of TiO2 Nanofibres on Selected Bronchoalveolar Parameters in Acute and Subacute Phase - Experimental Study. Cent Eur J Public Health. 2013;21(3):165-70.

14. Skřehot PA, Rupová M. Nanosafety. Prague: Occupational Safety Research Institute; 2011. (In Czech.)

15. Li J, Tian M, Cui L, Dwyer J, Fullwood NJ, Shen H, et al. Low-dose carbon-based nanoparticle-inducedeffects in A549 lung cells determined by biospectroscopy are associated with increases in genomic methylation. Sci Rep. 2016;6:20207. doi: 10.1038/srep20207.

16. Ema M, Hougaard KS, Kishimoto A, Honda K. Reproductive and developmental toxicity of carbon-based nanomaterials: a literature review. Nanotoxicology. 2016;10(4):391-412.

17. Mushtaq G, Khan JA, Joseph E, Kamal MA. Nanoparticles, neurotoxicity and neurodegenerative diseases. Curr Drug Metab. 2015;16(8):676-84.

18. Lomer MC, Thompson RP, Powell JJ. Fine and ultrafine particles of the diet: influence on the mucosal immune response and association with Crohn's disease. Proc Nutr Soc. 2002;61(1):123-30.

19. Tinkle SS, Antonini JM, Rich BA, Roberts JR, Salmen R, DePree K, et al. Skin as a route of exposure and sensitization in chronic beryllium disease. Environ Health Perspect. 2003;111(9):1202-8.

20. 20 Šimon P. Assessing the risks arising from the use of nanotechnology in foodstuff and fodder [Internet]. Bratislava: STU; 2008 [cited 2016 Mar 14]. Available from: http://www.mpsr.sk/download.php?fID=1721. (In Slovak.)

21. Hurbánková M. Solid aerosols and health. In: Šulcová M. Čižnár I. Fabiánová E. Public health. Bratislava: Veda; 2012. p. 372-88. (In Slovak.)

22. NANOFORCE project. State of the Art - Report Existing Safety Procedures and Nanotech Related Legislation [Internet]. 2012 [cited 2016 Mar 10]. Available from: http://www.nanoforceproject.eu/docs/defaultdocument-library/nanoforce_state_of_the_art_report.pdf.

23. Hartl S, Fries R, Giovanna DD, Klein J, Micheletti C, Laganis J, et al. Nanoforce. Book of recomendation for the European Commission: excerpt [Internet]. 2013 [cited 2016 Mar 10]. Available from: http://www. nanoforceproject.eu/docs/area-download/nanoforce_book_of_recommendations_excerpt_final.pdf?sfvrsn=2.

24. Surová S. Nanoforce 2014 ZCHFP F. In: Nanoforce Roundtable; 2014 Jan 23; Bratislava [Internet]. Bratislava: Association of Chemical and Pharmaceutical Industry SR; 2014 [cited 2016 May 20]. Available from: http://www.zchfp.sk/?vyber=21\#k16. (In Slovak.)

25. Fabiánová E. Nanoparticles and the recent knowledge about their effects on health. In: Nano Info Day; 2012 Sep 19-20, Svit [Internet]. Bratislava: Association of Chemical and Pharmaceutical Industry SR; 2012 [cited 2016 Apr 25]. Available from: http://www.zchfp.sk/?vyber=21\#k7. (In Slovak.)

26. Magdolenova Z, Drlickova M, Henjum K, Rundén-Pran E, Tulinska J, Bilanicova D, et al. Coating-dependent induction of cytotoxicity and genotoxicity of iron oxide nanoparticles. Nanotoxicology. 2015;9 Suppl 1:44-56.

27. Vojtíšek M, Pechout M, Dittrich L, Štolcpartlová J. Measurement of nanoparticles in the air in Sporilov - preliminary results [Internet]. Prague: Prague City Hall; 2014 [cited 2016 Feb 3]. Available from: http://medetox. cz/wp-content/uploads/2014/07/2014-14_PS-Sporilov-2014-07-09_vysledky.pdf. (In Czech.)

28. Görner P, Witschger O, Bau S, Wrobel S. Measuring exposure to nanoparticles in the workplace: SZU 29th Consulting day, Prague, 2009 Sep 
17 [Internet]. Paris: Institut National de Recherche et de Sécurité; 2009 [cited 2016 Feb 3]. Available from: http://www.szu.cz/uploads/documents/cpl/Materily_ze_seminaru/Materialy_2009/gorner_17.9.09.pdf . (In Slovak.)

29. Savolainen K, Alenius H, Norppa H, Pylkkänen L, Tuomi T, Kasper G. Risk assessment of engineered nanomaterials and nanotechnologies - a review. Toxicology. 2010;269(2-3):92-104.

30. Filling the knowledge gaps for safe nanotechnology in the workplace: a progress report from the NIOSH Nanotechnology Research Center, 2004-2011 [Internet]. Atlanta, GA: NIOSH Nanotechnology Research Center; 2012 [cited 2016 Apr 27 ]. Available from: http://www.cdc.gov/ niosh/docs/2013-101/pdfs/2013-101.pdf.

31. Regulation (EC) No $1333 / 2008$ of the European Parliament and of the Council of 16 December 2008 on food additives [Internet]. Strasbourg: European Commision; 2008 [cited 2016 Apr 27]. Available at: http:// eur-lex.europa.eu/legal-content/EN/TXT/PDF/?uri=CELEX:32008R13 $33 \&$ from $=\mathrm{EN}$.

32. Regulation (EU) No 528/2012 of the European Parliament and of the Council of 22 May 2012 concerning the making available on the market and use of biocidal products [Internet]. Strasbourg: European Commision; 2012 [cited 2016 Apr 29]. Available at: http://eur-lex.europa.eu/ LexUriServ/LexUriServ.do?uri=OJ:L:2012:167:0001:0123:en:PDF.

33. Regulation (EC) No 1223/2009 of the European Parliament and of the Council of 30 November 2009 on cosmetic products [Internet]. Strasbourg: European Commision; 2009 [cited 2016 Apr 29]. Available at: http://eur-lex.europa.eu/legal-content/EN/TXT/PDF/?uri=CELEX:320 09R1223\&from $=$ EN.

34. Commission Regulation (EU) No 10/2011 of 14 January 2011 on plastic materials and articles intended to come into contact with food [Internet]. Strasbourg: European Commision; 2011 [cited 2016 Apr 29]. Available at: http://eur-lex.europa.eu/LexUriServ/LexUriServ.do?uri=OJ:L:2011: 012:0001:0089:en:PDF.

35. Regulation (EC) No 1907/2006 of the European Parliament and of the Council of 18 December 2006 concerning the Registration, Evaluation,
Authorisation and Restriction of Chemicals (REACH) and establishing a European Chemicals Agency [Internet]. Strasbourg: European Commision; 2006 [cited 2016 Apr 29]. Available at: http://eur-lex.europa.eu/ LexUriServ/LexUriServ.do?uri=OJ:L:2007:136:0003:0280:en:PDF.

36. Communication from the Commission to the European Parliament, the Council and the European Economic and Social Committee - second regulatory review on nanomaterials [Internet]. Strasbourg: European Commision; 2012 [cited 2016 Apr 29]. Available at: http://eur-lex.europa. eu/LexUriServ/LexUriServ.do?uri=COM:2012:0572:FIN:en:PDF.

37. Senjen R. Nanomedicine - new solutions or new problems? [Internet]. Brussels: HCWH Europe; 2013 [cited 2016 Apr 29]. Available at: https:// noharm-europe.org/sites/default/files/documents-files/2462/HCWH $\% 20$ Europe\%20Nanoreport.pdf.

38. Schwirn K, Tietjen L, Beer I. Why are nanomaterials different and how can they be appropriately required under REACH? Environmental Sciences Europe. 2014; 26:4. doi: 10.1186/2190-4715-26-4.

39. E-fact 72: tools for the management of nanomaterials in the workplace and prevention measures [Internet]. European Agency for Safety and Health at Work; 2013 [cited 2016 May 20]. Available from: https://osha. europa.eu/sk/tools-and-publications/publications/e-facts/e-fact-72-toolsfor-the-management-of-nanomaterials-in-the-workplace-and-preventionmeasures/view.

40. Savolainen K, Backman U, Brouwer D, Fadeel B, Fernandes T, Kuhlbusch T, et al. Nanosafety in Europe 2015 - 2025: towards safe and sustainable nanomaterials and nanotechnology inovations [Internet]. Helsinki: Finish Institute of Occupational Health; 2013 [cited 2016 Apr 27]. Available from: http://www.ttl.fi/en/publications/Electronic_publications/ Nanosafety_in_europe_2015-2025/Documents/nanosafety_2015-2025. pdf 